\title{
Using neural network approaches, geophysical well logs and laboratory data to estimate petrophysical parameters of an Albian carbonate reservoir in Campos Basin, Southeast Brazil
}

\author{
A. Abel G. Carrasquilla, UENF/LENEP Macaé - RJ, Brazil
}

Copyright 2021, SBGf - Sociedade Brasileira de Geofísica.

This paper was prepared for presentation during the $17^{\text {th }}$ International Congress of the Brazilian Geophysical Society held in Rio de Janeiro, Brazil, $16-19$ August 2021.

Contents of this paper were reviewed by the Technical Committee of the $17^{\text {th }}$ International Congress of the Brazilian Geophysical Society and do not necessarily represent any position of the SBGf, its officers or members. Electronic reproduction or storage of any part of this paper for commercial purposes without the written consent of the Brazilian Geophysical Society is prohibited.

\begin{abstract}
In this article, direct and stochastic approaches of artificial neural network were utilized to estimate petrophysical parameters, such as, porosity $(\phi)$, permeability $(k)$ and water saturation $(\mathrm{Sw})$, of a Albian carbonate reservoir of the Campos Basin, Southeast Brazil. A data set, consisting of geophysical well logs and laboratory data, was used to study the post-salt carbonate reservoir of this basin. The laboratory data corresponds to $\phi$ and $\mathrm{k}$, while the logs were gamma ray (GR), density (RHOB), neutronic porosity (NPHI), shallow resistivity (RXO), deep resistivity (RT) and sonic (DT). The log data was, initially, filtered and smoothed to eliminate spurious values, using wavelet transforms and cubic interpolation, respectively. Then all the data were normalized on the same scale, because there is an exceptionally large difference in magnitude between them. The statistical study of the data showed that there is a high positive correlation between $\phi$, DT, NPHI and RXO and, a high negative correlation with $\mathrm{RHOB}$. The permeability $\mathrm{k}$ did not show high correlations with any log or even with $\phi$, but there are high negative corrections between the RHOB log and the NPHI and DT logs. Histograms and quantile graphs show, on the other hand, that the logs NPHI, RHOB, DT and $\phi$ present normal distribution, as the other data are shown with bimodal distribution. The boxplots show that the RHOB, NPHI and RT logs have small standard deviations, whereas in the GR, RXO and DT logs are moderate, and only the RT log has a lot of outlier data. Singular value decomposition, principal component analysis, clustering and dendrogram cutting show, still, that the dataset can be grouped into basically two main sets: reservoir and seal rock. After all of this, we set out for an estimate with neural network backpropagation, using the approaches of Levenberg - Marquart and Bayesian Regularization, both in the training and adjustment stages of the experimental $\phi$ and $\mathrm{k}$ data, and Sw calculated by Archie equation, in a reference well and a blind test with another well of the same oilfield. The results, from the use of these artificial neural network approaches, show that the processes were accurate and fast, presenting high values of Pearson's correlation coefficient.
\end{abstract}

